\title{
e-HR
}

\section{Presenteeism - how it can be managed and even used to the benefit of the unwell who want to work and the employer organization}

\section{Simon Barnes}

Simon Barnes is Managing

Director at Dinamiks Ltd,

Chichester, UK.

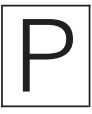

resenteeism is a relatively new description to describe employees who turn up for work feeling unwell and put in a shift if they are not told to go home. In many ways, it is the opposite of absence from work caused by sickness or pretending to be sick. But it might also be a lead-in to the latter, that is to "taking a sickie". Employers, beware!

With today's emerging new ways of working - from home, coffee shops, airport lounges and trains, thanks to the cloud and laptops and other mobile devices - the unwell can work if they really want to, but not necessarily by turning up at the workplace and spreading a virus around. If their employer has moved all files and software applications to the cloud, working from anywhere with a 3G, 4G or wifi/broadband connection can be very easy.

However, it is not only the cloud that is changing the way we work and making people turn up for work when sick, depressed or run down or too soon after an operation. Workaholism, the protestant work ethic, devotion to the employer organisation or the strong use of conscience - and in some cases, simply the need to earn money, including a bonus - are all drivers of presenteeism.

\section{Risk and reputation}

Apart from possibly being a prelude to taking time off for fake sickness, presenteeism, like over-working, can be a route to unintentionally suffering from stress or greater stress and its associated risk of human error and therefore a risk to the economic and reputation of the employer organisation.

The risk is real but on the plus side the input of skilled staff, whether stressed or sick, might be essential for the completion on time and to budget of a critically important project. However, employers have a duty of care to their staff, meaning they should take all steps that are reasonably possible to ensure their health, safety and wellbeing.

That could open up an employer to charges and possible subsequent legal action by an employee, about the care provided being inadequate. On the other hand, if the employer organisation deploys its duty of care and has a record of the employee's attitude, behaviour, attendance at work and his or her performance, all in a digital audit trail, it might have a strong case of defence. Indeed, the employee may be persuaded by it not to initiate action. 
How can presenteeism be managed? And does it always lead to reduced performance? It may well do especially if it helps to spread illness in the workplace. Should key workers who are unwell, but whose input is essential for a project, be tolerated at work - or will that depend on whether they have a cold or the flu and are sent home?

Presenteeism is a complex issue and can be managed alongside holidays, sickness and other time off on an absence management system. All the absences affecting staff who are well, including holiday and other leave, and genuine sickness, when it happens - if it ever happens in some cases! apply just as much to those who present with presenteeism as those who do not.

As we work towards a more engaged and inclusive work environment, challenges like absenteeism and presenteeism will become less customary and less detrimental to the employee and the business. In the interim, companies need the metrics to be able to address any underlying issues.

With the advent of technologies such as smart phones and cloud computing anyone can work from anywhere at any time - and many people do when they are not well enough to travel to or attend the office, because of a cold or a recovery from an operation.

\section{Gaining information and analysing it}

Presenteeism can be managed by collecting information and analysing it in real time. Cloud-based tools can be used for those purposes to give the employer organisation instant feedback and, over time, patterns of behaviour.

The tools provide easy-to-use tick boxes for answers to questions, and over a length of time will show any patterns behind absenteeism or presenteeism. Is employee $x$ off sick more on a Friday or Monday (thereby simply wanting to extend the weekend, or could be sick after a weekend of drinking)? Is employee y in on Mondays even when not feeling well or is definitely ill? If so, "y" would be displaying classic signs of presenteeism.

Management of the tools is typically by a manager or team leader, or the head of HR, or can be outsourced to an external HR consultant or firm. The appointed manager will have access to all employees' replies to any tick box question via a restricted area of the tools, and to all analysis carried out by the tool, its results produced in an "at a glance", easily understood format and retained for year on year comparisons.

Staff are sent automated email reminders they that have questions to answer, if they have not answered them by pre-determined times and dates. The questions can be solely about absence, or its opposite, presenteeism and are designed to complement other questions that, together, optionally, show patterns of individual's performance over time as well as compliance with meeting objectives and targets.

The patterns will also show whether an employee takes time off for sickness at irregular or regular intervals. The former might indicate genuine sickness, the latter, the opposite, which brings me to the subject of absence and its management. Absence, whether caused by annual or compassionate leave, sickness, training (or giving lectures) can be managed in such a way as to not only allow the employer to allocate human resources to plug gaps but also to improve the productivity of an individual team, department or organisation.

Management of presenteeism can likewise be used to move resources around if those who are genuinely unwell but insist on working are less effective at their job - which must be expected to be the case in most instances. Through replying to tick box questions/answers, the working unwell can have their hours and performance tracked just as effectively as those who do not turn up for work due to sickness or other reason.

Modern, or next generation, absence management tools are typically replacements for paper-based charts that hang on office walls to be filled in by staff and management. Dinamiks Ltd has taken the tools to a new level with Dinamiks HR Absence Management, which is different in that it not only allows for the management absence and presenteeism but can also link them to the performance and training (and mentoring) of employees, managers included.

Any employees who are apparently unwell but wish to work, and their employer allows them to, can be put through the same employee development programmes as their colleagues, and participate in annual or more frequent performance appraisals, with allowances made for their condition and likely reduced performance.

\section{Improving productivity - and morale}

The combination of the cloud and managing presenteeism means that the unwell could participate in flexi working, or more flexi working than their colleagues, and even aim towards improving their productivity if they wish to try for that. A mix of working from home and at the employer organisation might suit both parties well as part of flexi working and could see productivity 
rise without any other effort to achieve that. Time that would have been spent commuting could be used for working instead, if that is what unwell employees want, and could lead to their morale improving as well as an improvement in productivity.
As I trust I have made clear in this article, presenteeism has more elements to it than might at first seem to be the case. If it, and the unwell who want to work, can be managed, the employer can avoid pitfalls and appreciate the contribution the unwell can make.
More at Dinamiks.com

\section{Corresponding author}

Simon Barnes can be contacted at: simon@dinamiks.com 